\title{
A Review of Effects of Covid-19 on Geriatric Population
}

\author{
A Sri Anjana Priyanka and Swarupa Chakole \\ ${ }^{1}$ Medical Intern, Jawaharlal Nehru Medical College,Datta Meghe Institute of \\ Medical Sciences (Deemed to be University),Wardha(442001), Maharashtra ,India. \\ ${ }^{2}$ Professor, Department of Community Medicine, Jawaharlal Nehru \\ Medical College,Datta Meghe Institute of Medical Sciences \\ (Deemed to be University),Wardha(442001), Maharashtra ,India \\ Corresponding author email: anjana.aalapati@gmail.com
}

\section{ABSTRACT}

The world witnessed the COVID-19 pandemic and the impacts on vulnerable sections of the society.The older people were tormented a lot by as an effect of physiological and psychological consequences of the infection. The management was targeted towardspreventive measures and medical treatment of comorbidities. But, the psychological component of this older populationwasbadly ignored. The elderly population suffered a lot due to isolation, lockdown, restriction of movements and ignorance. Reports of older getting ill-treated have been seen during this outbreak. The critical sufferers included those staying alone at home, having cognitive or psychological impairments and down trodden.It resulted in notable drastic and indelible effects on the health and wellness of the elderly, making their life miserable and putting their lives at stake.As per the policies reported throughout the world, a comprehensive care model needed to be effectively implemented throughout the pandemics. People staying away from families needed to be given special attention. Out of all the antecedently mentioned hazard factors raised the psychological well-being weight of the previous and might effectively have an effect on private satisfaction. Tragically, analysis known with this field continues to be scant. Barely any editorials have checked out the requirement of distinctive support for the older psychological wellbeing, referencing medical care and cautioning regarding loneliness and social break down. This article tries to review the impact of COVID-19 on Geriatric population.

\section{KEY WORDS: COVID-19, ELDERLY, GERIATRIC , PANDEMIC, PSYCHOLOGICAL WELL-BEING}

\section{INTRODUCTION}

The world is attempting another worldwide well-being danger. The Covid infection 2019 (COVID-19) has arisen as a "daily existence transformer" for human development. completely different countries have packed up their fringes, worldwide economies are cut and travel has been restricted around the world. Billions are isolated at their own homes making an attempt to control the happening (Singhal, 2020).

Biosc Biotech Res Comm P-ISSN: 0974-6455 E-ISSN: 2321-4007

\section{crossef}

Identifiers and Pagination

Year: 2021 Vol: 14 No (6) Special Issue

Pages: $141-147$

This is an open access article under Creative

Commons License Attribn 4.0 Intl (CC-BY).

DOI: $h t t p: / / d x . d o i . o r g / 10.21786 / b b r c / 14.6 .32$
These exceptional occasions have stricken intensely everyone's lives, notably weak areas. Archetypes of the world are the older, WHO divertingly are liable to each the malady and so the internment is forced to control it. Effectively inclined by the seriousness along with casualty of COVID-19 as a result of old enough ,the psychological suggestions likewise can usually be a lot of vital for them (Banerjee et al., 2020). Isolation, disregard, absence of self-government, and dangers of misuse are few commonly detected branches of this pandemic.

Social removal will have an effect on their psychological prosperity, increasing the danger of mental issues. With a quickly maturing society, once the amount of individuals over sixty years is a lot more distinguished than that of under-five youngsters, guaranteeing all-encompassing security of elderly is of most extreme significance throughout such organic fiascos. Reviews from outbreaks earlier show that the elders on the verge of elevated

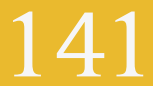


danger for each intense and finish of the day outcomes. info from the old style font "diseases" of the plague at intervals the thirteenth century, the Spanish contagious disease of 1918, the Asiatic cholera, and so the intense respiratory disorder (SARS) show the swollen weaknesses of the recent apart from swollen case casualty rates. as a result of the globe is up to now at intervals within the early grasps of the COVID-19 pandemic, it may even be advantageous to hunt out the way to diminish the dismalness and secure the non-public satisfaction of the skillful world. Keeping this in foundation, this critique appears at the fascinating difficulties tried by the matured, the social ramifications, endeavors to feature the ways that forward.

\section{DISCUSSION}

\begin{abstract}
"Age group and Senility": the Two Usual Vulnerabilities: Almost 4,000,000 are influenced worldwide with the COVID-19 and virtually 3 lakhs relinquished thereto, the total number ascending as we tend to speak. The World Health Organization (WHO) confirmed it as an epidemic of public health emergency of international concern within a month of its birthplace, as associate degree episode of quite a huge scope influencing every part of life has not been found in gift day times. The responsible specialist of COVID-19, novel Covid SARS-CoV-2, is definitely less deadly than its previous congeners (SARS and geographic region metastasis disorder) but considerably additional infectious with distended human-human transmission risk (Lai et al., 2020).
\end{abstract}

One among the explanations being that the feasibility to the infection in mobile and completely different areas are as long as concerning fourteen days, but the particular logical agreement thereon is nonetheless to be originated. Lion's share of contaminations are mellow, nonetheless few have respiratory illness and intense metastasis hassle disorder, which may within the finish prompt mortality. Moreover, the seriousness and casualty of the unwellness is higher within the older, immunological disorder patients, and people with previous metastasis sicknesses, persistent clinical problems even as underidentification of symptoms (Feng and Zhang, 2020). The previous are at associate degree exceptional danger of each one among these weaknesses along. Throughout the principal wave in China within the contaminated, two hundredth of passings were matured over sixty years (Feng and Zhang, 2020).

Chinese Center for unwellness management and hindrance has unconcealed a casualty pace of three.6\% in 60-69 years' age bunch which may transcend eighty years (Wu and McGoogan, 2020). Homogeneous discoveries are resounded in nations with high COVID-19 passings, for instance, Italy, Spain, Asian nation, Iran, and therefore the US (Sohrabi et al., 2020). It's to boot been seen that in mature age, there are often mortalities even while not respiratory organ contribution. it's known with imprecise multi-organ disappointment and blood poisoning (Wu and McGoogan, 2020). An associate degree age-wise similar investigation done by Liu et al. Amid hospitalized instances of COVID-19 incontestable, the older gathering (over fifty five years) had distended span in the medical clinic stay, delayed clinical healing, distended respiratory organ inclusion, faster movement of the unwellness, and ultimately distended fatalities (Liu et al., 2020). The necessity for mechanical ventilation and oxygen treatment had increased within the maturity gathering, and their blood to boot indicated diminished lymphocytes and C-receptor macromolecule, the 2 of that are markers of decent safe reaction in the infection. In concern with skillfulness, in progress uncontrolled sicknesses, (for example, diabetes, high blood pressure, inflammation, degenerative joint disease, and intellectual decay), various meds, and distended demand for hospitalizations as a result of various factors any increment the impotence of the previous.

Animal tissue issues, endocrinopathies, neural structure mishaps, degenerative joint disease, and alternative provocative conditions are perceived to regulate resistant reaction and confound the cascade of COVID-19s sickness (Yang et al., 2020). The generality of these problems increments within age, during this manner build on danger. The studies also have likewise incontestable the psychological weight of older people as a result of the outbreak . Drawn out community based seclusion was documented as "genuine general well-being worry" for now as the previous because it builds the hazards of vessel, system, neurocognitive, and psychological well-being connected disorders (Gerst-Emerson et al., 2015). A long term intervention investigation has been indicated that social disconnection expands generality as for misery, uneasiness, grief , and sleep deprivation seen in additional established adults (Santini et al., 2020). whereas separating them is basic for his or her own actual security, upholding it while not oversight can expand dejection, deteriorate temperament state, cut price their self-governance, and influence their general prosperity.

Emotional eudaimonia and Coronavirus unwellness 2019: connection for the old: COVID-19 emergency could be extraordinary internationally. Out of all the antecedently mentioned hazard factors raise the psychological wellbeing weight of the previous and might effectively have an effect on private satisfaction. Tragically, analysis known with this field continues to be scant. Barely any editorials have checked out the requirement of distinctive support for the older psychological wellbeing, referencing medical care of associations as a desire and cautioning regarding loneliness, social breaking down because the important branches in the pandemic and resultant imprisonment (Banerjee et al., 2020).

Apart from the dreaded, danger of misuse, and segregation throughout COVID-19, various elderly live miles away from their children. Western nations, for instance, the (U. S.) and (U. K.) are too influenced with this outbreak with expanded death rates. The previous whose children board these nations stay in an exceedingly consistent condition of stress, dread, and impotence. The other aspect, the failure to urge the actual existence and care 
forward assuming that they're hospitalized or unwell throughout this worldwide imprisonment will raise the evangelical delicacy. Even as documented before, effective affiliation, but a selection, cannot sub to a "adoring touch" got from the family. Besides, the top or deprivation of their companion/children thanks to the contamination, with imprisonment and destruction comfortable last rituals, will in addition exacerbate the despondence.

These will be autonomous danger elements for late-life ill-being, which may be clinically polymorphic, under detected throughout totally different desires throughout pandemics likewise increasing the danger for suicides. A web review led in Hubei, China for 1074 people indicated diminished cognitive prosperity, expanded despondence, and fewer lucky nature of rest within the previous (age > 55 years), contrasted with substance misuse and uneasiness that were a lot of within the younger population (Ahmed et al., 2020). Another close enough long examination led from a hundred ninety Chinese urban areas for 1738 members proclaimed the next pace of the physical (substantial) manifestations connected within nervousness, expanded injury marks, and diminished rest, that expanded within age and also were known with detachment, seen pressure, and unfold of eudaimonia knowledge by media (Wang et al.

20200 despite what can be expected, associate degree investigation by Huang and Zhao documented younger people having a lot of taxing and tension indications than their senior counterparts (Huang et al., 2020) associate degree investigation from Northern Italy expressed individual components (tactile and psychological shortfalls,sequels, and multi drug therapy), pathogenic variables (neutrophil counts in infection, upset state, and fragility), and ecological parts (social disconnection, regulation, and high thought affirmations) because the important dangers for psychological state in the previous and disclosed 30\%-half medical specialty partners of the COVID-19 in daze, unsettling, gloom, but the particular predominance of every wasn't rumored (Serafini et al., 2020). The worldwide (Brazil, Portugal, and Norway) report about the emotional eudaimonia of the previous throughout COVID-19 suggested towards expanded institutionalization, dread of mortality , shame, agerelated bias, and separating from the family because the components for increasing mental comorbidity during this people (Monteiro etal., 2020).

Risk decrease, actual security, and the social trustiness have planned ventures by the writers keen about the case vignettes that they need talked about. Distinctive at risk areas within the previous are those which facilitate less community help, living alone, with previous cognitive problems and also indigent. Misuse of any substance connected to the complexities documented before will increment each dismalness and death rate. A foothold paper on "Coronavirus and substance misuse problems" by the International Society of Addiction medication issues the concern of addictive practices adding to the final eudaimonia bother and distinguishes grown-ups
> 60 years previous at altogether higher risk (Farhoudian et al., 2020). Baker together with Clark as currently prescribed a psychological thanks to contend with manage the social seclusion throughout the pandemic by modification the infective danger, steady guiding conferences, psychological education in the families, and proceeded with association in care (Baker et al., 2020)..

The extraordinary weaknesses of the old inclining them to the outbreak fear are :

1. Fragility (the elderly illness completes natural and psycho social weakness of a person) that's known with development limitation, lack of healthy sustenance, and helpless insusceptibility (Fried et al., 2001)

2. Forlornness, disregard, separation, and helpless sustenance (all the a lot of thus in recent thought homes and controlled arrangements)

3. Tactile problems (troubles in vision and hearing) which will keep them from taking part in it safe .

4. Ongoing sickness, polypharmacy, expanded medical services want, and actual facilitation .

5. Debilitated intellectual capacities (memory, handling rate, thought process, and communication) which deteriorate as age increases will keep themselves appreciating, clinging to prudent directions. People influenced with dementedness could have conduct problems and wandering inclinations which will boost difficulties of keeping them secluded currently and once more of such bursts .

6. Social separating might not typically be conceivable (different people in several jobs are related to their thoughts, together with native help for the people the World Health Organization stays alone). a lot of seasoned grown-ups frequently live by propensities created over years that structure a big piece of their day. A sudden disturbance of this timetable may be damaging. Day by day strolls within the recreation center or to satisfy companion gathering and wish to urge day by day basics will prompt expanded introduction to the contamination and henceforward expanded dread. various saw grown-ups discover it's terribly testing to mentally acknowledge the "prohibitive" pointers of movability given by the general public authority for holding the episode, in spite of whether or not they comprehend the necessity .

7. The older in all probability will not apprehend and are fresh regarding the legitimate information known with sickness, within the inside of the many "data contamination" that's currently common. Disarray and misguided judgments could give birth to resistance to prudent steps, defective medicines, and overmedication

8. Lacking the COVID-19 tests and after small location will modify them to the well transporters of the exceptionally communicable disease.

9. Existential problems with "what when me" and "shouldn't one thing be aforesaid regarding my family" attributable to the dread of death are traditional in additional seasoned grown- 
ups. Self-disregard may result from a tough headed acquiescence to outbreak circumstances, unsupportive the danger of contamination and outweighing the danger. The opposite worry is in the additional established grown-ups is that of AN honorable passing, that is undermined throughout the progressing internment, travel limitations, social removal. An acceptable dread emerges of an abrupt and desolate dying in courageousness and loneliness, aloof from the family, while not the last need that one had. Basically, the usual setting of the secured "demise" turns into a lot of distinguished concern rather than death itself, which may influence ardent prosperity. spirituality could be a vital adapting issue for the old,( Lai et al., 2020) and also the interference of strict ceremonies as bit of end customs for the despoiled will forestall solid sorrowful

10. Psychosocial weakness, significantly now and again of internment and isolation: dejection, uneasiness, and vulnerability can give ascent to onerous issues, a sleeping disorder, and protracted pressure. Anguish and mourning attributable to misfortune or removing from their friends and family may be crucial and constant. They're likewise at expanded danger for post-traumatic stress disease, if pressure is delayed. Alarming, self-destruction hazard in addition a couple of times a lot of within the older public and is frequently underreported (Lebret et al., 2006). A race emotional eudaemonia summary in China throughout this outbreak incontestable that thirty third of these over sixty years knowledgeable sorrow, heartsickness, nervousness, and a sleeping disorder (Qiu et al., 2020).

11. Coronavirus has achieved a selected modification within the study of sickness transmission and treatment of enslavement disorders (Marsden et al., 2020). Alcohol misuse, liquor addiction, and drinking due to stress have expanded universally auxiliary to the outbreak emergency. It's been conjectured that ethyl alcohol lessens versatile invulnerability and enhances the angiotensin-changing over catalyst a pair of receptors, that are the objectives of the SARS-CoV-2 infection (da Silva et al., 2020). The sudden internment in Asian nation has prompted increment in bemused withdrawals, which may be deadly if not treated, significantly for the recent. Utilization of corrupted liquor and wood alcohol are alternative dangerous threats (Arya and Gupta, 2020) Opioids replacement cure will get hampered, extreme smoking in addition demolishes the previous pneumonic states of lot of seasoned grownups motioning them to the pathogenic impacts of COVID-19. Considerably, precautions and prudent steps are obstructed with a helpless cure trying to find adding the endless loop of any substance misuse, that has well a lot of unfavorable well-being impacts on the seniors .

12. Absence of native help and elementary living civilities in those living alone attributable to the internment will create endurance a a lot of distinguished issues than the danger of sickness. Taking into consideration that the native partners oblige various homes with obscure pointers of cleanliness and security, they risk being well transporters of the sickness. The frequent adds to this vulnerability along with dread knowledge of the recent whom they have served. This is often a "double edged blade" because the seniors living alone at often times subject to their each day facilitate, and nevertheless uneasy and unfortunate regarding getting infection (Officer and Fuente, 2018). This usually serves a big wellspring of weakness, each physical and ardent

13. Trouble in the advanced availability: thanks to completely different reasons, for instance, absence of commonality, psychological or tangible shortages, and challenges in adjusting to a different coaching, various senior residents in all probability will not be capable enough to stay in grips with their friends and family through long vary informal communication and the virtual conference techniques, that are recommended overall throughout the COVID19 emergency for remaining connected socially. Significantly a lot of seasoned grown-ups living alone in all probability will not have the mandatory facilitation after they get to interface for all intents and functions with their families. This may boost the frustration and vulnerability. Despite the very fact that advanced association appears, by all accounts, to be an even handed substitute, it's appeared in before examinations that the older prefer individual correspondence and care, rather than the virtual interactions. In this pandemic circumstance, people were staying really "isolated" adds to the dejection and social separation.

Shame of "ageism :" Predecessor to illicit : The other angle to , the disgrace of discrimination. Regularly, the older are usually the minimized populace. Despite the very fact that typically folks are schooled to take and wear down the suffering age, the intrinsic dread of "maturing," "losing imperativeness," and end have created "aging " a standard "community malevolence." The World Health Organization characterizes discrimination as "the generalizing, bias, victimization people captivated with the age."( Nelson, 2004) The community likens maturing with the deprivation of "appeal with magnificence" of young and also later has identified the danger to differing types of the mature ageism misuse. So much shame associated degreed misuse will erupt from time to time of a occurrence that has an age-explicit liability (Chang, 2020).

The replacement economical survey was given by Chang et al. (2020) connected discrimination with varied pessimistic biological and psychological outcomes. Traditional colloquial substance throughout this outbreak , like "Gracious, you're typically associate degree objective, you must be protected," "the elderly are passing on, thus you higher stay separate just in case you might get contaminated" or "you have to be compelled to take additional mind, or, altogether chance you'll taint others" seem to be clearly generous nonetheless loaded down with rebuke and shame. The previous are inclined 
to possess constant respiratory disorder, hindering respiratory organ sickness, basic virus prompting in progress hack, raw throat and contagious disease like indications that are effortlessly confused with those of the COVID-19 infected . This could prompt communal isolation, shame , obstructed cognitive prosperity. Congestion, disregard, and helpless care in mature old age homes at different tributary variables.

Strain and grief severely affects resistance and later will expand the inclination to any illness. self-government and self-nobility is hampered throughout the imprisonment that they're encountering, that can in addition weaken the disposition, hunger, and also sleep (Gaidhane et al., 2020). Several of them live alone and are battling with the basic civilities, as an example, food, native utilities, and cleanliness aboard the waiting apprehension of the pandemic (Jachak et al., 2020; Joseph et al., 2020; Joshi et al., 2020; Khatib et al., 2020; Lakhkar et al., 2020). A number of key health problems in geriatric patients were addressed in studies of Jain et al. (2012), Dua et al. (2016) Kumar et al. (2018; 2016).

The Covid -19 pandemic has awaned a emergency call for all older population (Butola et al., 2020; Dasari et al., 2020). The dormant favouritism and former disgrace will show as cruelty and ill-usage against the previous, significantly throughout ensnarement and imprisonment circumstances once various families are investment important unbuffered energy, quite ever. Animosity, substance misuse, nonsensical thinking, and familial force progression will get intense throughout the outbreak . This could raise senior ill-usage, a real worry of the COVID-19 emergency.

\section{CONCLUSION}

The additional seasoned grown-ups have more scope of difficulties throughout the pandemics, but most square measures are preventable. Coronavirus is still in the initial stages. Considerably additional psychological horribleness is much needed within the months to follow, and therefore the prosperity administrations ought to be prepared equivalently. The Indian Pandemic Act, 1897 requires an update within the real discern. This might be a good occasion including the protection and prosperity of additional seasoned grown-ups throughout the pandemics. The weaknesses of the older and their conditions ought to be by and enormous attended with coordinated and economical endeavors in the slightest degree levels. The seniors are also overwhelmed and delicate as a result of the right age, nonetheless they're not frail. With regard to the author "The recent will expertise every torment" from his ancient La Peste (The Plague),the versatility of the recent may be astonishing, if satisfactorily thought of and therefore the immature will always get from their qualities. However one treats their seniors throughout a catastrophe, shapes of what treatment they get in the advanced emergencies. Coronavirus conveys an additional open door for the equivalent.

\section{REFERENCES}

Ahmed, M.Z., Ahmed, O., Aibao, Z., Hanbin, S., Siyu, L. and Ahmad, A., 2020. Epidemic of COVID-19 in China and associated psychological problems. Asian journal of psychiatry, 51, p.102092.

Armitage, R. and Nellums, L.B., 2020. COVID-19 and the consequences of isolating the elderly. The Lancet Public Health, 5(5), p.e256.

Arya, S. and Gupta, R., 2020. COVID-19 outbreak: Challenges for Addiction services in India. Asian journal of psychiatry, 51, p.102086.

Baker, E. and Clark, L.L., 2020. Biopsychopharmacosocial approach to assess impact of social distancing and isolation on mental health in older adults. British journal of community nursing, 25(5), pp.231-238.

Banerjee, D., Kosagisharaf, J.R. and Rao, T.S., 2020. 'The dual pandemic' of suicide and COVID-19: A biopsychosocial narrative of risks and prevention. Psychiatry research, p.113577.

Butola, L.K., Ambad, R., Kute, P.K., Jha, R.K., Shinde, A.D. and DMIMS, W., 2020. The Pandemic of 21st Century-COVID-19. Journal of Evolution of Medical and Dental Sciences, 9(39), pp.2913-2919.

Chang, E.S., Kannoth, S., Levy, S., Wang, S.Y., Lee, J.E. and Levy, B.R., 2020. Global reach of ageism on older persons' health: A systematic review. PloS one, 15(1), p.e0220857.

da Silva, J. and Testino, G., 2020. Risks of alcohol abuse, alcoholism and stress-related drinking during the COVID-19 pandemic. Alcoholism and Drug Addiction/ Alkoholizm i Narkomania, 33(1), pp.95-98.

DASARI, V. and DASARI, K., 2020. Nutraceuticals to Support Immunity: COVID-19 Pandemic-A Wake-up Call. Journal of Clinical \& Diagnostic Research, 14(7). Dua, S., Sharma, K., Juneja, R., Kalakoti, P., Kamble, M. and Subramanian, P., 2016. Unusual presentation of unilateral intra-orbital optic nerve pilocytic astrocytoma of the juvenile type in a geriatric patient. Journal of Clinical Neuroscience, 25, pp.143-144.

Farhoudian, A., Baldacchino, A., Clark, N., Gerra, G., Ekhtiari, H., Dom, G., Mokri, A., Sadeghi, M., Nematollahi, P., Demasi, M. and Schütz, C.G., 2020. COVID-19 and substance use disorders: Recommendations to a comprehensive healthcare response. An international society of addiction medicine practice and policy interest group position paper. Basic and Clinical Neuroscience, 11(2), p.133.

Feng, Z., Li, Q., Zhang, Y. 2020. Novel coronavirus pneumonia emergency response epidemiology, The epidemiological characteristics of an epidemic of 2019 novel coronavirus diseases (COVID-19) in China. Zhonghua Liu Xing Bing Xue Za Zhi, 41, pp.145-51 
Fried, L.P., Tangen, C.M., Walston, J., Newman, A.B., Hirsch, C., Gottdiener, J., Seeman, T., Tracy, R., Kop, W.J., Burke, G. and McBurnie, M.A., 2001. Frailty in older adults: evidence for a phenotype. The Journals of Gerontology Series A: Biological Sciences and Medical Sciences, 56(3), pp.M146-M157.

Gaidhane, S., Khatib, N., Zahiruddin, Q.S., Gaidhane, A., Telrandhe, S. and Godhiwal, P., 2020. Depression, anxiety and stress among the general population in the time of COVID-19 lockdown: A cross-sectional study protocol. International Journal of Research in Pharmaceutical Sciences, 11(Special Issue 1).

Gerst-Emerson, K. and Jayawardhana, J., 2015. Loneliness as a public health issue: the impact of loneliness on health care utilization among older adults. American journal of public health, 105(5), pp.10131019.

Huang, Y. and Zhao, N., 2020. Generalized anxiety disorder, depressive symptoms and sleep quality during COVID-19 outbreak in China: a web-based crosssectional survey. Psychiatry research, 288, p.112954. Jachak, S., Phansopkar, P. and Naqvi, M.W., 2020. Impact of covid-19 in India, a disastrous pandemic outbreak. International Journal of Research in Pharmaceutical Sciences, 11(Special Issue 1).

Jain, S., Kumar, S., Deshmukh, P.T., Yohannan, D. and Sudarshan, K., 2012. Congenital aural stenosis with first branchial cleft fistula, presenting with recurrent facial nerve palsy, in an elderly patient. Journal of Clinical Gerontology and Geriatrics, 3(1), pp.42-44.

Joseph, M.B., Pohekar, S., Raut, A. and Patil, M., 2020. The palliative care and covid-19 pandemic. International Journal of Research in Pharmaceutical Sciences, 11(Special Issue 1).

Joshi, K., Acharya, N., Acharya, S., Joshi, S. 2020. A Grave Situation with COVID in the Gravid: A Narrative Review. International Journal of Research in Pharmaceutical Sciences, 11 (1), pp. 496-99. https://doi. org/10.26452/ijrps.v11iSPL1.2837.

Khatib, M.N., Gaidhane, S., Khatib, M., Ahmed, M., Gaidhane, A. and Syed, Z.Q., 2020. SARS-CoV and SARS-CoV-2: Similar viruses with different trajectories. Wutan Huatan Jisuan Jishu, 16(5).

Kumar, S., Bhayani, P., Hathi, D. and Bhagwati, J., 2018. Hyponatremia initial presenting feature of normal pressure hydrocephalus in elderly patient: a rare case report. Journal of Gerontology and Geriatrics, 66, pp.156-157.

Kumar, S., Jain, S., Agrawal, S. and Honmode, A., 2016. Impact of serum magnesium levels in critically ill elderly patients-A study in a rural teaching hospital. Journal of Clinical Gerontology and Geriatrics, 7(3), pp.104-108. Kumar, S., Lonkar, Y., Amale, A., Diwan, S.K. and
Banode, P., 2013. Gross hematuria due to renal arteriovenous malformation successfully treated with embolization in an elderly patient. Journal of Clinical Gerontology and Geriatrics, 4(2), pp.62-64.

Lai, C.C., Shih, T.P., Ko, W.C., Tang, H.J. and Hsueh, P.R., 2020. Severe acute respiratory syndrome coronavirus 2 (SARS-CoV-2) and coronavirus disease-2019 (COVID19): The epidemic and the challenges. International journal of antimicrobial agents, 55(3), p.105924.

Lakhkar, B.B., Guru, B., Damke, S., Damke, S. 2020. Most Susceptible Duo in COVID-19 Crisis: A Literature Review.Perinatology, 21(3), pp. 112-23.

Latchoumi, T.P., Ezhilarasi, T.P. and Balamurugan, K., 2019. Bio-inspired weighed quantum particle swarm optimization and smooth support vector machine ensembles for identification of abnormalities in medical data. SN Applied Sciences, 1(10), pp.1-10.

Lebret, S., Perret-Vaille, E., Mulliez, A., Gerbaud, L. and Jalenques, I., 2006. Elderly suicide attempters: characteristics and outcome. International Journal of Geriatric Psychiatry: A journal of the psychiatry of late life and allied sciences, 21(11), pp.1052-1059.

Liu, K., Chen, Y., Lin, R. and Han, K., 2020. Clinical features of COVID-19 in elderly patients: A comparison with young and middle-aged patients. Journal of Infection, 80(6), pp.e14-e18.

Marsden, J., Darke, S., Hall, W., Hickman, M., Holmes, J., Humphreys, K., Neale, J., Tucker, J. and West, R., 2020. Mitigating and learning from the impact of COVID-19 infection on addictive disorders. Addiction.

Monteiro-Junior, R.S., Carneiro, L.S., Barca, M.L., Kristiansen, K.M., Sampaio, C.A., Haikal, D.S.A., Antunes, L., Leão, L.L. and Deslandes, A.C., 2020. COVID-19 pandemic: a multinational report providing professional experiences in the management of mental health of elderly. International Psychogeriatrics, 32(10), pp.1153-1156.

Nelson, T.D. ed., 2004. Ageism: Stereotyping and prejudice against older persons. MIT press.

Officer, A. and de la Fuente-Núñez, V., 2018. A global campaign to combat ageism. Bulletin of the World Health Organization, 96(4), p.295.

Qiu, J., Shen, B., Zhao, M., Wang, Z., Xie, B., Xu, Y. 2020. A nationwide survey of psychological distress among Chinese people within the COVID-19 epidemic: Implications and policy recommendations. Gen Psychiatry, 33, pp.100213.

Santini, Z.I., Jose, P.E., Cornwell, E.Y., Koyanagi, A., Nielsen, L., Hinrichsen, C., Meilstrup, C., Madsen, K.R. and Koushede, V., 2020. Social disconnectedness, perceived isolation, and symptoms of depression and anxiety among older Americans (NSHAP): a longitudinal mediation analysis. The Lancet Public 
Health, 5(1), pp.e62-e70.

Serafıni, G., Bondi, E., Locatelli, C. and Amore, M., 2020. Aged patients with mental disorders in the COVID-19 era: the experience of Northern Italy. The American Journal of Geriatric Psychiatry, 28(7), pp.794-795.

Singhal, T., 2020. Review on COVID19 disease so far. Indian J Pediatr, 87(4), pp.281-6.

Sohrabi, C., Alsafı, Z., O’Neill, N., Khan, M., Kerwan, A., Al-Jabir, A., Iosifidis, C. and Agha, R., 2020. World Health Organization declares global emergency: A review of the 2019 novel coronavirus (COVID-19). International journal of surgery, 76, pp.71-76.

Wang, C., Pan, R., Wan, X., Tan, Y., Xu, L., McIntyre, R.S., Choo, F.N., Tran, B., Ho, R., Sharma, V.K. and Ho,
C., 2020. A longitudinal study on the mental health of general population during the COVID-19 epidemic in China. Brain, behavior, and immunity, 87, pp.40-48.

Wu, Z. and McGoogan, J.M., 2020. Characteristics of and important lessons from the coronavirus disease 2019 (COVID-19) outbreak in China: summary of a report of 72314 cases from the Chinese Center for Disease Control and Prevention. Jama, 323(13), pp.1239-1242.

Yang, J., Zheng, Y., Gou, X., Pu, K., Chen, Z., Guo, Q., Ji, R., Wang, H., Wang, Y. and Zhou, Y., 2020. Prevalence of comorbidities in the novel Wuhan coronavirus (COVID19) infection: a systematic review and meta-analysis. Int J Infect Dis, 10. 